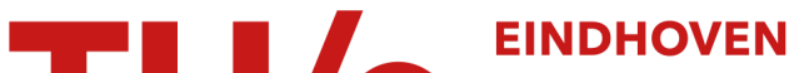 UNIVERSITY OF TECHNOLOGY
}

\section{Relaxed dimensional tolerance whispering gallery microbends}

Citation for published version (APA):

Stabile, R., \& Williams, K. A. (2011). Relaxed dimensional tolerance whispering gallery microbends. Journal of Lightwave Technology, 29(12), 1893-1898. https://doi.org/10.1109/JLT.2011.2150198

DOI:

10.1109/JLT.2011.2150198

Document status and date:

Published: 01/01/2011

Document Version:

Accepted manuscript including changes made at the peer-review stage

Please check the document version of this publication:

- A submitted manuscript is the version of the article upon submission and before peer-review. There can be important differences between the submitted version and the official published version of record. People interested in the research are advised to contact the author for the final version of the publication, or visit the $\mathrm{DOI}$ to the publisher's website.

- The final author version and the galley proof are versions of the publication after peer review.

- The final published version features the final layout of the paper including the volume, issue and page numbers.

Link to publication

\section{General rights}

Copyright and moral rights for the publications made accessible in the public portal are retained by the authors and/or other copyright owners and it is a condition of accessing publications that users recognise and abide by the legal requirements associated with these rights.

- Users may download and print one copy of any publication from the public portal for the purpose of private study or research.

- You may not further distribute the material or use it for any profit-making activity or commercial gain

- You may freely distribute the URL identifying the publication in the public portal.

If the publication is distributed under the terms of Article $25 \mathrm{fa}$ of the Dutch Copyright Act, indicated by the "Taverne" license above, please follow below link for the End User Agreement:

www.tue.nl/taverne

Take down policy

If you believe that this document breaches copyright please contact us at:

openaccess@tue.nl

providing details and we will investigate your claim. 


\title{
Relaxed Dimensional Tolerance Whispering Gallery Microbends
}

\author{
Ripalta Stabile and Kevin A. Williams, Member, IEEE
}

\begin{abstract}
A new class of highly compact photonic microbend exploiting whispering gallery propagation is analyzed. Critical design dimensions are relaxed by using multimode waveguiding. A small outer sidewall radius enables tight arbitrary angle of rotation for the guided light, and the inner radius is reduced beyond the caustic radius to minimize the impact of the microbend dimensions on losses. Whispering gallery operation is compared with single-mode microbend operation using a combination of full-vectorial wave-equation models and 2-D and 3-D finite-difference time domain models. The dependence of loss on fabricated dimension is shown to be reduced by an order of magnitude. Waveguide width variations of $\pm 100 \mathbf{~ n m}$ lead to loss variations of only $\pm 0.01 \mathrm{~dB}$ in the whispering gallery regime, contrasting favorably with $\pm 0.10 \mathrm{~dB}$ loss variations for the single-mode regime for a $20 \mu \mathrm{m}$ radius and for $1.5 \mu \mathrm{m}$ input waveguide widths. Smaller radius microbends show comparable trends albeit with higher losses and increased sensitivity to width variations. The sensitivity of microbend loss to small changes in narrow waveguide width is attributed to the excitation of a restricted mode group. Moving the inner sidewall beyond the caustic radius allows relaxed tolerance light propagation in the whispering gallery regime. Losses down to $0.2 \mathrm{~dB} / 180^{\circ}$ and polarization conversion of down to $-25 \mathrm{~dB} / 180^{\circ}$ are predicted.
\end{abstract}

Index Terms-Optical losses, optical polarization, optical waveguides, rib waveguides, waveguide bends.

\section{INTRODUCTION}

High-density photonic integrated circuits are expected to require the routing of electromagnetic waves with ever-smaller bend radii. Photonic bandgap defects [1]-[3], total internal reflection mirrors [4]-[8], and resonant corners [9] have received extensive attention for such ultracompact light manipulations. However, such approaches can require relatively long tapered waveguides to match the tightly confined optical modes to less tightly confined waveguides. In many cases, the range of feasible rotation angles is also constrained. Curved waveguides offer arbitrary waveguide rotation and modest loss using a conventional process technology. However, the most detailed theoretical studies have been performed for relatively large bend radii in the hundreds of micrometers regime [10]-[12]. For radii of order tens of micrometers, high refractive index contrast is required in the plane of the microbend to minimize radiation losses. This is readily achieved with deeply etched

Manuscript received November 02, 2010; revised March 04, 2011; accepted April 17, 2011. Date of publication May 05, 2011; date of current version May 27, 2011. This work was supported by the Dutch STW Technology Foundation.

The authors are with COBRA Research Institute, Technical University of Eindhoven, Eindhoven 5600MB, The Netherlands (e-mail: r.stabile@tue.nl; K.A.Williams@tue.nl).

Color versions of one or more of the figures in this paper are available online at http://ieeexplore.ieee.org.

Digital Object Identifier 10.1109/JLT.2011.2150198 waveguides [13]-[16] and has been exploited in ultracompact arrayed waveguide gratings [17], [18]. Performance does, however, become increasingly sensitive to waveguide bend modal properties, fabrication tolerance, and polarization rotation, leading even to a body of research on polarization converters [19]-[21]. To reduce bend radii even further toward the micrometer level, researchers have considered high refractive index contrast in both vertical and horizontal waveguiding planes to also minimize substrate losses. Micrometer radius single-mode waveguides can, however, become highly sensitive to nanoscale dimensional variations [5], [7], [8], sidewall tilt [5], [22], surface roughness [5], [23], and substrate leakage [23], leading to performance variations from process to process and potentially even within the circuits themselves.

Multimode waveguide structures have been recently proposed for relaxed tolerance integrated circuit elements including integrated parabolic mirrors [24], multimode interference reflectors mirrors [25], and microdiscs [26]. Multimode waveguides with selective modal excitation offer a means to radically reduce the device footprint without imposing fabrication critical structures. In this paper, we propose multimode structures as a fabrication tolerant microbend for high-density photonic wiring.

A whispering gallery microbend design is proposed with bending radii in the range micrometers to a few tens of micrometers. Low-loss fabrication tolerant design is studied through the analysis of mode propagation in 2-D and 3-D and through the study of the modal composition. The whispering gallery microbend concept is presented in Section II. The simulation environment is described in Section III, isolating the dominant loss mechanisms. Section IV explores the transition from single mode to whispering gallery regime operation through the variation of the inner bend radius. This allows an assessment of viable design parameter ranges and thus dimensional tolerances. The impact of varied radial dimensions additionally allows the comparative study of the two operating regimes in Section V. Modal decomposition highlights the role played by higher order modes in the sensitivity of loss to waveguide width. Finally, Section VI addresses conversion between polarization states for the excited modes. This allows a comprehensive assessment of the design space and thus of dimensional tolerance for whispering gallery microbends.

\section{Whispering GALLery Regime Microbend}

The whispering gallery regime allows wave propagation without defining the inner waveguiding boundary [27], [28]. The excited modes consist of propagating fields guided by the outer radius and characterized by an optical inertia which 


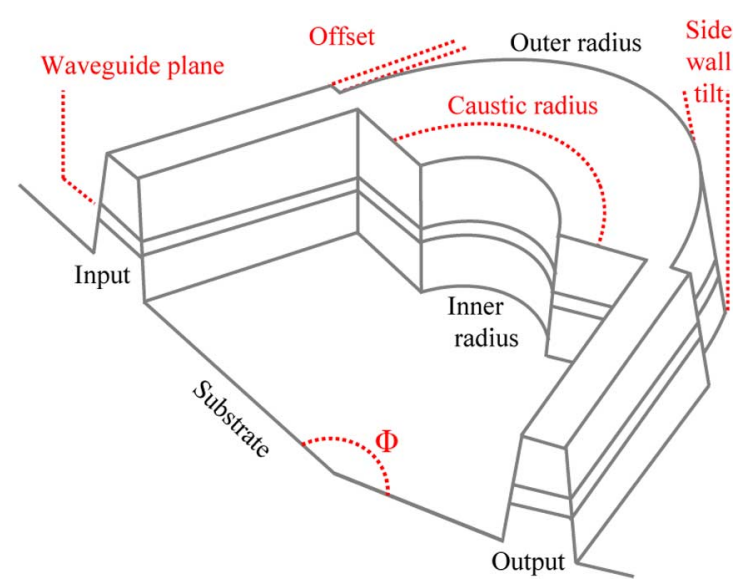

Fig. 1. Whispering gallery microbend concept.

prevents the fields from penetrating inward beyond an inner caustic radius. The inner caustic radial boundary is defined as $R_{c}=m / n_{r} k_{o}$ [28], where $m$ is the azimuthal mode number, $n_{r}$ is the dielectric refractive index, and $k_{o}$ is the wave number. The whispering gallery modes themselves are commonly defined in terms of the radially propagating solutions to the Helmholtz equations for closed dielectric waveguides [29], [30]. An analogous form of propagation in a whispering gallery regime also allows mode propagation near the outer boundary of an open dielectric waveguide [31]-[33]. The open waveguide structure can take the form shown in Fig. 1. In the vertical plane, the waveguide is defined by low refractive index cladding layers above and below the high refractive index waveguide plane. The vertical sidewalls are defined by air boundaries at the outer radius to minimize radiative loss. The inner radius is set within the caustic radius where it does not play a dominating role.

Light is input with a straight waveguide and exits with a second straight waveguide by means of a whispering gallery microbend with bending angle $\Phi$, as shown in Fig. 1. The sidewalls are shown with a tilt, recognizing that mask erosion during fabrication can lead to off-vertical sidewalls. Modal propagation in the bend leads to an asymmetric power distribution and a mismatch at the junctions between the straight waveguides and the microbend. Optimum power coupling at the straight-to-bend junctions is obtained by laterally offsetting the outer edge of the straight waveguides with respect to the outer radius. This accounts for the displacement of the guided modes in the waveguide bends [34]. In practice, these offsets are explicitly defined in the photolithographic mask for the waveguides and therefore do not vary with fabricated waveguide width. Nonetheless, a number of parameters highlighted in Fig. 1 can be sensitive to fabrication:

1) the outer bend radius for the microbend;

2) the inner bend radius;

3) the sidewall tilt, shown off-vertical in Fig. 1;

4) the input and output waveguide widths.

In this study, we define a single mode for the input guide, and study the sensitivity of losses to the first three microbend parameters. Losses studied include coupling loss, radiative loss, substrate loss, and loss through polarization conversion. Scattering from rough sidewalls may be treated independently and has been studied elsewhere.

\section{Simulation ToOLS}

The range of dimensions considered for the microbends is not ideally suited to any one of the currently implemented simulation techniques. The designs with larger outer radii require considerable CPU time and memory when simulated using finite-difference time domain (FDTD) techniques and do not offer detailed insight into modal evolution. Smaller bend radii rotate the fields too rapidly for vectorial mode solvers. Four commercially available simulation tools are, therefore, used to allow for maximum insight into the mode of operation. All structures are first simulated using the 2-D FDTD tool. Insight into modal evolution is developed by using a 2-D mode solver and 3-D mode propagation tool for the larger designs for regimes where the techniques are still valid [35]. Finally, a 3-D FDTD solver allows the investigation of power transfer between modes in orthogonal polarization states and the estimation of substrate loss.

The semianalytical fully vectorial mode solver, Fimmwave [36], is used to study the modal composition for the whispering gallery microbends. This 2-D tool uses the definition for an epitaxially resolved, air-clad, rectangular rib waveguide as input. The solver uses the complex film mode matching method [37] to compute the modes supported in the larger radius waveguide bends. Lateral, $5 \mu \mathrm{m}$ thick perfectly matching layers are used to suppress spurious numerical reflections from the boundaries of the simulation. The vertical effective refractive index is also calculated with the mode solver to perform 2-D FDTD simulations resolved in the waveguide plane. The 3-D mode propagation tool, FIMMprop, uses the eigenmode expansion method [38] to quantify the mode resolved power in the microbends using the single-mode straight waveguide launch.

The fully vectorial FDTD solver, Omnisim [39], is used to simulate the propagation of light through the microbend structures. Perfectly matched layers with thickness of $8 \mu \mathrm{m}$ are used for all the boundaries to suppress artificial reflections [40]. For the 2-D and 3-D simulations, the grid spacings along the axes are 0.1 and $0.05 \mu \mathrm{m}$, and simulated areas and volumes are 250-1850 $\mu \mathrm{m}^{2}$ and $2750-20000 \mu \mathrm{m}^{3}$, respectively, for the range of radii considered. 3-D FDTD simulations take the most resources. A desktop computer using 4 GB RAM and a single core processor requires $16 \mathrm{~h} \mathrm{CPU} \mathrm{time} \mathrm{to} \mathrm{simulate} \mathrm{the} \mathrm{largest} \mathrm{radius} \mathrm{structures.}$ Arbitrary angles of rotation can be simulated for the microbend, but the simulation environment restricts the placement of the most comprehensive diagnostic tools to vertical and horizontal axes. Simulations are, therefore, performed for $90^{\circ}$ and $180^{\circ}$ bends in this study.

Vertical confinement is defined by InP cladding layers around a quaternary $(\mathrm{Q})$ waveguiding layer of relatively high refractive index. The upper cladding, waveguiding layer, and lower cladding are defined to be 2000,650 , and $2000 \mathrm{~nm}$ in thickness. For the operating wavelength of $1.55 \mu \mathrm{m}$, the refractive indexes of waveguide layer, cladding layers, and air are specified to be $3.29,3.19$ and 1 , respectively. Horizontal confinement is defined by a $2800 \mathrm{~nm}$ etch depth and is air-clad in the simulations [see 

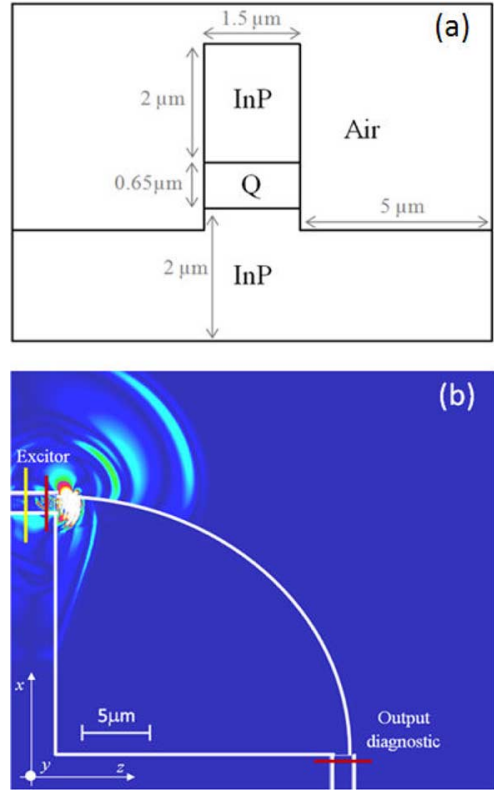

Fig. 2. (a) Cross section of the designed layer stacks for input waveguides. (b) 2-D FDTD model screen capture showing key-loss mechanisms and simulation diagnostic.

Fig. 2(a)]. A vertical effective refractive index of 3.28 is calculated for the deeply etched waveguide in Fig. 2(a). The range for single-mode operation is also identified for the input and output waveguides. The straight waveguide width is scanned using the film mode matching solver to quantify a range to represent single-mode operation. In the narrow waveguide limit, a single mode with nonzero sidewall loss of order $10^{-3} \mathrm{~cm}^{-1}$ is calculated for a width of $1.2 \mu \mathrm{m}$. In the wide waveguide limit, power in the higher order modes is measured to be less than $1 \%$ for a waveguide width up to $1.8 \mu \mathrm{m}$. An intermediate input straight waveguide dimensionally tolerant width of $1.5 \mu \mathrm{m}$ is, therefore, selected for subsequent simulations.

To study microbend waveguiding properties, the fundamental mode for the input straight waveguide is used as the exciting source. Fig. 2(b) shows the arrangement for propagation from a straight input waveguide through a $90^{\circ}$ microbend and into an output diagnostic sensor. An impulse excitation of duration 1.4 ps is used to ensure all power is recorded in the loss measurements. The screen capture shows the amplitude of the $x$-component of the electric field. For the imperfect offset, radiation losses are apparent as the optical power couples into the microbend.

\section{Optical Losses}

Coupling into the microbends is first studied by scanning the straight waveguide to microbend offsets for the range of simulated outer radii. The 2-D FDTD analysis is performed for microbends with outer radii varied from 3 to $30 \mu \mathrm{m}$. The inner radius is set to zero in this section and the angle of rotation is $180^{\circ}$. The offset is defined as the distance between the outer radius and the outer edge of the straight waveguide at the junctions as shown in Fig. 1. Coupling losses are summarized in Fig. 3.

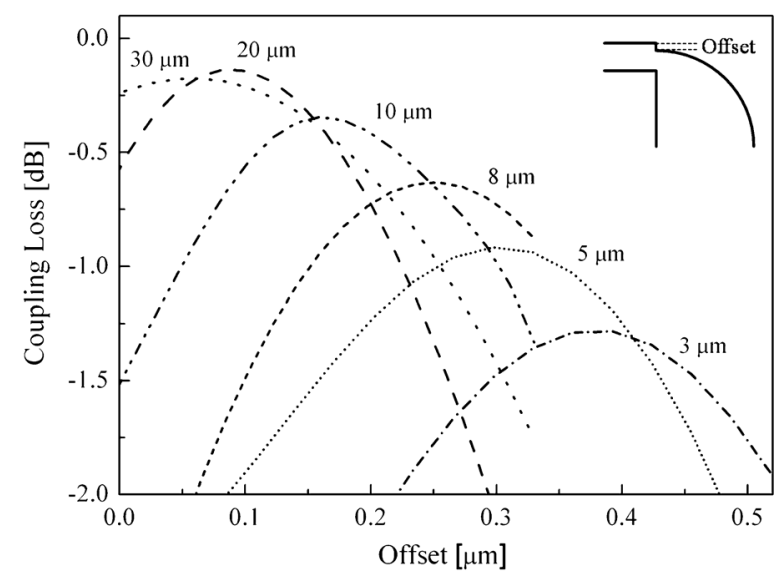

Fig. 3. Coupling loss into and out of varied outer radius microbends for a range of waveguide offsets. The offset definition is inset. Inner radius is set to zero.

Lower values of outer radius require increased offset values between bend and straight waveguides to balance the more pronounced optical mode shift. Outer radii larger than $30 \mu \mathrm{m}$ show a much reduced requirement for an offset, due to a negligible optical mode shift. For a loss variation of approximately $\pm 0.1 \mathrm{~dB}$, there is a tolerance of up to $\pm 60 \mathrm{~nm}$.

Simulations in Fig. 3 indicate the lowest loss operation for the $20 \mu \mathrm{m}$ radius design. Reducing the radius below $20 \mu \mathrm{m}$ leads to an increase in loss which may be attributable to imperfect mode matching. The mode is increasingly truncated as the offset is increased. The lost power is radiated outside of the microbend and scattered at the straight-to-bend junctions. These losses might, however, be reduced through the inclusion of a tapering input and output guide. Higher values of simulated radius lead to a more complex higher order mode excitation. This is evident in the observed losses for the $30 \mu \mathrm{m}$ design and has been separately suppressed by increasing the inner radius from zero toward to the caustic radius.

Simulated losses between the input and output TE-like guided modes are resolved into contributions from waveguidemicrobend coupling and in-plane radiation loss. Total losses are obtained from the ratios of calculated electromagnetic fluxes at the sensors in the input and output waveguides. The coupling loss is calculated using mode sensors located at the input, on both sides of the waveguide offset, and at the output waveguide. The difference between the total loss and the coupling losses gives the in-plane radiation loss. Simulations are performed for $180^{\circ}$ microbends in order to increase the net losses. Calculations presented in Fig. 4 for the radius range 3 to $30 \mu \mathrm{m}$ highlight the role of the outer radius on the net loss for the microbends. Optimum waveguide offsets between the straight waveguides and microbends are used throughout.

Total losses for $180^{\circ}$ microbends are simulated to be lower than $0.4 \mathrm{~dB}$ for radii for the range from 15 to $30 \mu \mathrm{m}$ for optimized waveguide offsets. At $20 \mu \mathrm{m}$ radius, the loss is only weakly dependent on outer radius, indicating an excellent tolerance to submicrometer dimensional variations. While radiation loss is relatively low for these modest outer radii, it begins to increase as the radius approaches micrometer dimensions. However, this represents a minor contribution to the total loss, and 


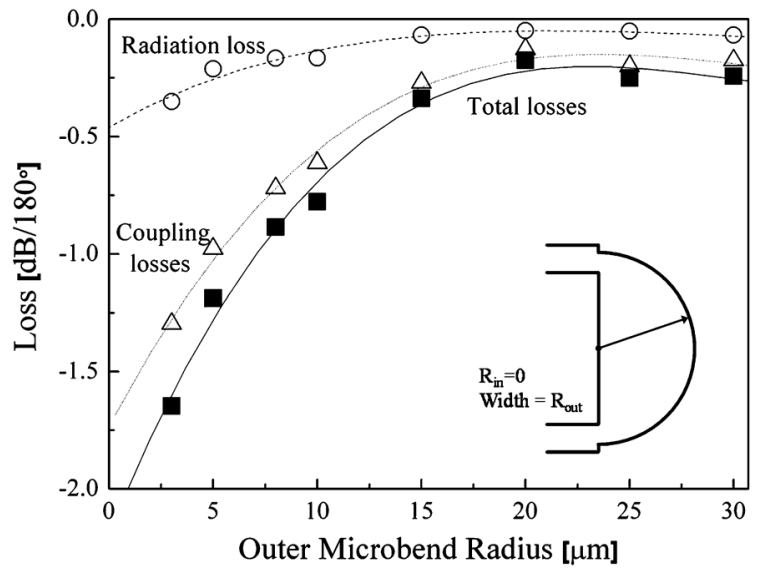

Fig. 4. Microbend losses as a function of outer radius. Inner radius is set to 0 $\mu \mathrm{m}$. In-plane radiation losses shown as open circles, coupling losses between straight waveguides and the microbend shown as open triangles, and total losses shown as filled squares. The radial definitions are inset.

this is attributable to the strong confinement of the light in the deep-etched air-clad waveguide. For outer radii lower than 15 $\mu \mathrm{m}$, the increase in loss is dominated by the imperfect mode matching into the microbend. This indicates a limitation in the use of the simple waveguide offsetting for mode matching at these low bend radii and a potential role for a more sophisticated tapered mode coupling.

Further insight into the loss mechanisms may be derived using the fully vectorial mode solver simulation tool. For the $20 \mu \mathrm{m}$ radius microbend, $1.2 \%$ of the input power is coupled into radiative modes at the first waveguide offset and $0.2 \%$ of the power is coupled to the fundamental TM polarization. Leakage into the substrate is not accounted for using the 2-D FDTD solver, but comparable calculations using the 3-D FDTD solver are able to resolve an additional loss of order $1.4 \%$ via imperfect vertical confinement.

\section{Single-Mode And WhisPering-Gallery Regimes}

The transition from single-mode operation to whispering gallery regime is controlled through the definition of an inner sidewall radius. In the extreme case of a zero radius inner sidewall considered in Section IV, whispering gallery operation is observed. If the inner radius is defined within the structurally defined caustic radius, mode propagation becomes influenced by the inner sidewall. In this section, the role of the inner radius is studied for four outer sidewall radii, 5, 10, 15, and $20 \mu \mathrm{m}$ by performing 2-D FDTD simulations. Optimum offset values do not vary significantly with inner radius for bend widths exceeding $1.5 \mu \mathrm{m}$. Values are taken from Fig. 3 . The inner radius is increased from zero through to and beyond the value required for single-mode waveguide operation. The microbend waveguide width is now defined as the difference between the inner and the outer radii. Fig. 5 plots loss as a function of microbend width for all the four radii, from the most dimensionally tolerant $20 \mu \mathrm{m}$ outer radius design to the compact $5 \mu \mathrm{m}$ outer radius design. The inner radius is varied in steps of $0.025,0.030,0.040$, and $0.050 \mu \mathrm{m}$ for the $5,10,15$, and $20 \mu \mathrm{m}$ outer sidewall radial designs, respectively.

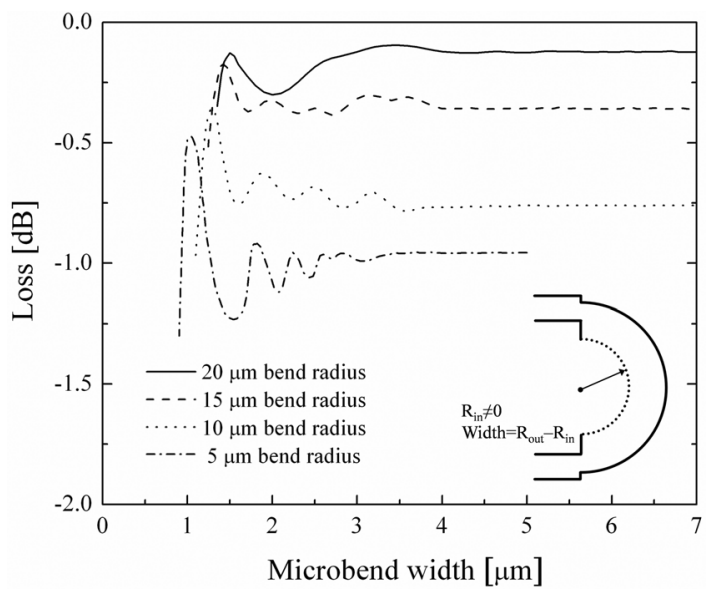

Fig. 5. Loss as a function of the microbend waveguide width. Four radii presented: $20 \mu \mathrm{m}$ (solid line), $15 \mu \mathrm{m}$ (dashed line), $10 \mu \mathrm{m}$ (dotted line), and $5 \mu \mathrm{m}$ (dash-dot line).

Loss data are plotted for microbend widths from the single mode through to the whispering gallery regime. The loss initially varies strongly with increasing waveguide width. However, as the microbend width tends toward the outer radius value, the loss becomes invariant with waveguide width, the inner radius has increased far beyond the caustic radius, and mode definition is no longer dependent on the inner radius: propagation occurs in the whispering gallery regime.

The sensitivity of loss to microbend width variations can be quantified by differentiating loss with respect to width. For the $20 \mu \mathrm{m}$ radius microbend design, a microbend width variation of $\pm 100 \mathrm{~nm}$ leads to loss variations of only $\pm 0.01 \mathrm{~dB}$ in the whispering gallery regime, contrasting favorably with \pm 0.10 $\mathrm{dB}$ loss variations observed in the single-mode regime. Comparable trends are observed for the smaller $5 \mu \mathrm{m}$ outer radius microbend (see dash-dot line in Fig. 5). Here, however, the variation in loss is even greater. $\mathrm{A} \pm 0.35 \mathrm{~dB}$ loss variation is observed for $\pm 100 \mathrm{~nm}$ feature variation in the single-mode regime, relaxing to $\pm 0.07 \mathrm{~dB}$ in the whispering gallery regime. This should be relaxed, however, for a narrower input waveguide width. Loss is increasingly dimensionally sensitive to feature size as the microbend width approaches the single-mode waveguide width.

The intensity profiles are studied as a function of microbend width in Fig. 6. 2-D FDTD simulations are performed with continuous stimuli to study the evolution of the radial peak position and $1 / \mathrm{e}^{2}$ width of intensity profiles for the range of microbend designs. Data for radial intensity peak position and $1 / \mathrm{e}^{2}$ width are presented for the four radii as a function of bend width in Fig. 6(a) and (b), respectively. Fig. 6(c) displays the intensity profiles calculated after a $180^{\circ}$ whispering gallery microbend.

Fig. 6(a) shows significant movement in the peak intensity for small fluctuations in small microbend widths. However, as the microbend width increases, the dependence is markedly reduced for all the outer radii considered. The peak radial intensity for the $20 \mu \mathrm{m}$ radius bend moves inwards by $100 \mathrm{~nm}$, in agreement with an observed increase in mode effective refractive index. The $1 / \mathrm{e}^{2}$ width also increases by $130 \mathrm{~nm}$, stabilizing as the whispering gallery regime is approached. The intensity 

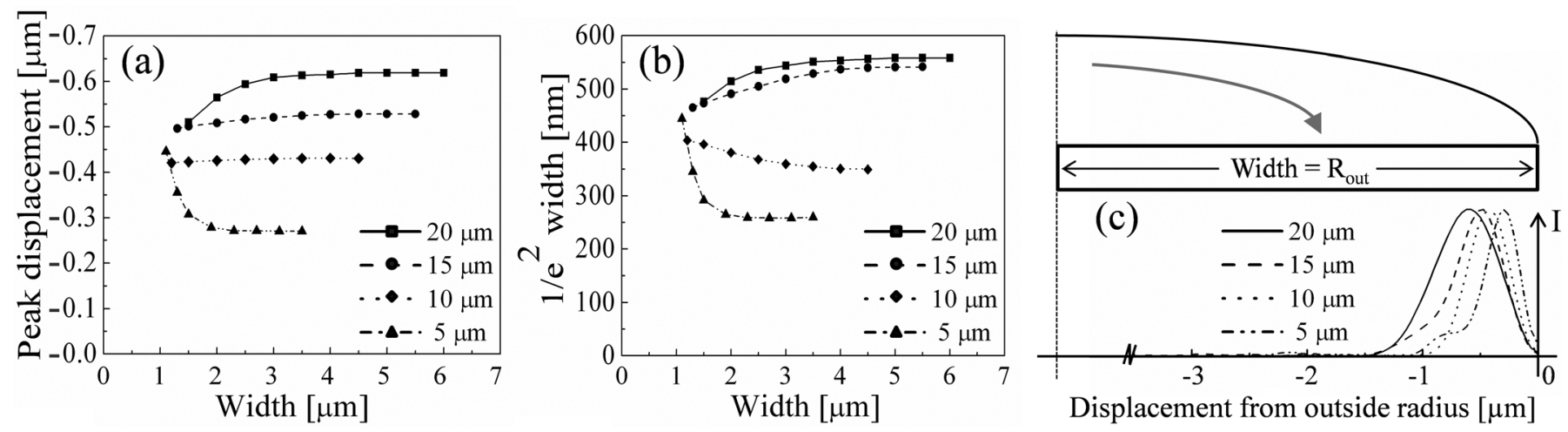

Fig. 6. Intensity distribution at the output of $180^{\circ}$ whispering gallery regime microbends. (a) Displacement of maximum intensity relative to outer radius. (b) $1 / \mathrm{e}^{2}$ width for the intensity. (c) Radial intensity profiles with a schematic whispering gallery microbend for reference.

TABLE I

Power Coupling Around a $20 \mu \mathrm{M}$ WhisPering Gallery Microbend

\begin{tabular}{cccccc}
$20 \mu \mathrm{m}$ radius & $\Phi=0^{\circ}$ & $\Phi=45^{\circ}$ & $\Phi=90^{\circ}$ & $\Phi=135^{\circ}$ & $\Phi=180^{\circ}$ \\
\hline $\begin{array}{c}\text { Fundamental } \\
\text { TE-like mode }\end{array}$ & $86.2 \%$ & $81.6 \%$ & $82.5 \%$ & $83.7 \%$ & $84.2 \%$ \\
\hline $\begin{array}{c}\text { First } \\
\text { TE-like mode }\end{array}$ & $7.6 \%$ & $6.1 \%$ & $5.9 \%$ & $3.2 \%$ & $1.2 \%$ \\
\hline $\begin{array}{c}\text { Second } \\
\text { TE-like mode }\end{array}$ & $2.0 \%$ & $1.9 \%$ & $2.1 \%$ & $1.0 \%$ & $0.04 \%$
\end{tabular}

profile is increasingly defined by the outer radius of the bend. The same behavior is observed for both 15 and $10 \mu \mathrm{m}$ radius bends, although with smaller peak shifts and $1 / \mathrm{e}^{2}$ width changes $(\leq 50 \mathrm{~nm})$. The intensity peak for the $5 \mu$ m radius bend moves outwards and narrows however with some evidence of higher order bend mode excitation in Fig. 6(c). This may explain the higher losses calculated for this radius bend.

The vectorial mode solver is used to resolve modal power for the range of $20 \mu \mathrm{m}$ microbend designs. Multiple simulations are subsequently performed to resolve modal power distributions as a function of microbend radial position for the whispering gallery microbend waveguide. Mode power distributions and evolution are shown in Table I as the optical power circulates the whispering gallery microbend.

Propagation simulations for a $20 \mu \mathrm{m}$ outer radius microbend with $0 \mu \mathrm{m}$ inner radius indicate a power coupling of $86.2 \%$ to the fundamental TE-like microbend mode from the fundamental TE-like mode in the straight input waveguide. $7.6 \%$ power couples to the first-order TE-like bend mode, $2.0 \%$ power couples to the second order TE-like bend mode, and $0.2 \%$ power couples to the fundamental TM-like microbend mode. The rest of the power is lost to radiative modes, but negligible power is observed in the modes beyond the second-order bend mode. After $180^{\circ}$ propagation, the guided power is mostly coupled to the fundamental TE-like mode (84.2\%). A comparison of the proportion of modal power as a function of propagation distance in Table I shows that there is a small amount of power exchanged between the modes.

The modal composition can be considered in terms of modal cutoff. For a $20 \mu \mathrm{m}$ radius bend, the fundamental first and second bend modes exhibit cutoff widths at 1.0, 1.4, and 2.2 $\mu \mathrm{m}$, respectively. Smaller cutoff widths are predicted for lower radii bends: the cutoff width for the fundamental TE-like mode in the $5 \mu \mathrm{m}$ radius bend is calculated to be $0.8 \mu \mathrm{m}$. Small microbend widths in the range $1-1.5 \mu \mathrm{m}$ lead primarily to fundamental mode excitation that is defined by both the inner and outer edge in the microbends. Losses reach minimum values for single-mode operation, but the tolerances to fluctuations in microbend width are strict. Moderate microbend widths in the range of 1.5 and $4 \mu \mathrm{m}$ allow the excitation of higher order bend modes, causing losses to be highly sensitive to variations in bend width.

An inspection of the spatially resolved intensity profile within the whispering gallery microbends allows a comparative analysis between the open boundaries considered in this study and the whispering gallery modes supported by closed resonators. Equivalent azimuthal mode numbers $m$ are estimated to be 59 , 124,188 , and 255 for outer radii of $5,10,15$, and $20 \mu \mathrm{m}$, respectively at $1.55 \mu \mathrm{m}$ wavelength by fringe counting at the radius of peak intensity. Fundamental bend mode propagation constants evaluated using the mode solver following [29] also predict equivalent $m$ values to within \pm 2 for each of the four radii considered.

\section{POLARIZATION CONVERSION}

Power transfer between modes in orthogonal polarization states is studied by resolving the microbend in three spatial dimensions. The modes of a curved waveguide are hybrid in nature and the off-vertical tilted sidewalls increases power exchange between modes. The sidewall angle is implemented by tapering the vertical cross section of the waveguide structure to allow a range from $0^{\circ}$ (perfectly vertical) to $10^{\circ}$ off-vertical. The range includes $1^{\circ}-2^{\circ}$ off-vertical tilts typical for 

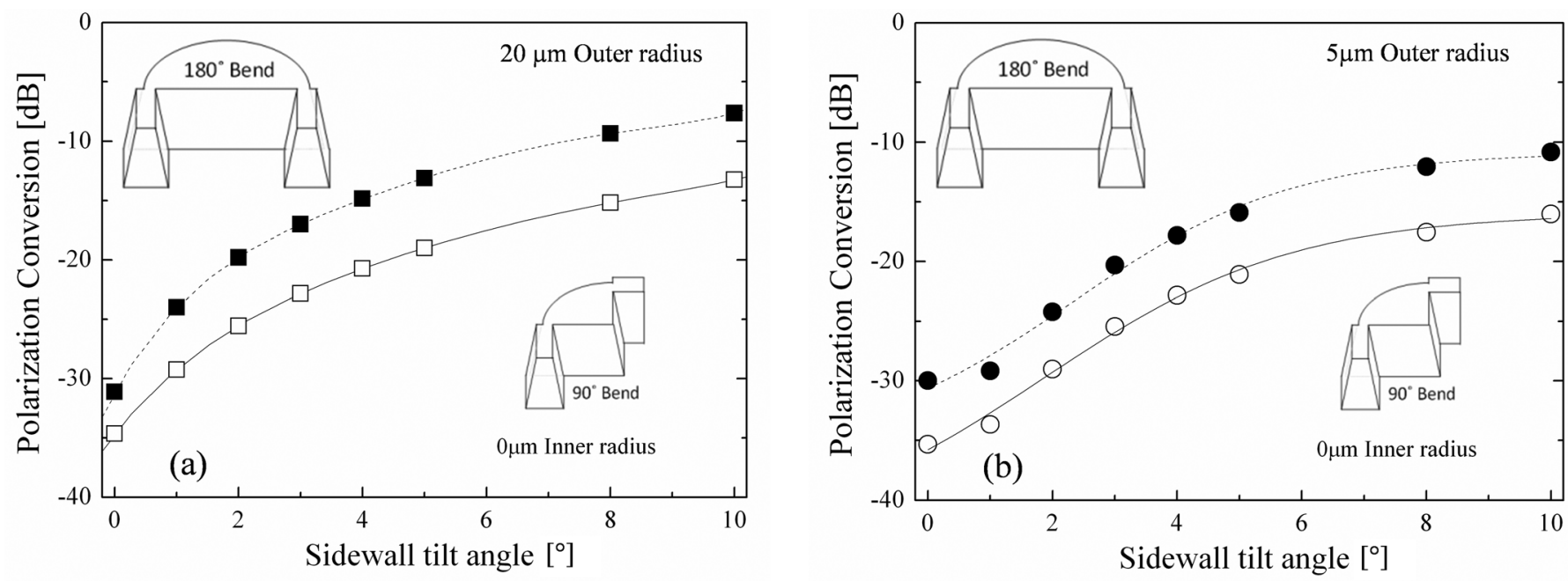

Fig. 7. Dependence of polarization conversion on sidewall tilt for $90^{\circ}$ and $180^{\circ}$ microbends for (a) $20 \mu \mathrm{m}$ outer radius and (b) $5 \mu \mathrm{m}$ outer radius.

inductively coupled plasma etching through to sidewall angles approaching $10^{\circ}$ more typical of reactive ion etching.

Polarization conversion is defined as the ratio of the output power associated with the TM-like polarization state to the input power associated with the TE-like polarization state. 3-D FDTD simulations are performed with a discretization grid sufficient to resolve the tilt and the smallest features of the device. Simulations are presented for both $90^{\circ}$ and $180^{\circ}$ microbends with outer radii of 5 and $20 \mu \mathrm{m}$ in Fig. 7.

The increased sidewall tilt angle leads to a marked increase in TE-to-TM coupling per unit length. The differences between the microbends of differing lengths are primarily due to differences in propagation distance. However, polarization conversion of below $-25 \mathrm{~dB} / 90^{\circ}$ can be achieved if a sidewall tilt of below $2^{\circ}$ is maintained. The residual polarization rotation value of $-35 \mathrm{~dB} / 90^{\circ}$ results from the hybrid nature of the modes in a curved waveguides [10]. The rotation angle affects the propagation constant of the excited modes in the microbend, increasing the phase shift between the excited TE and TM modes and thus the magnitude of the polarization rotation. For the dimensions considered in Fig. 7, this leads to a cumulative buildup as seen by comparing data for $90^{\circ}$ and $180^{\circ}$ microbends. This increases up until the polarization conversion length, which is estimated to be 200 and $150 \mu \mathrm{m}$ for $20 \mu \mathrm{m}$ radius single-mode microbends with $0^{\circ}$ and $10^{\circ}$ sidewall tilts [21].

The influence of the waveguide microbend width on the polarization state is also investigated. For the worst case simulation for $10^{\circ}$ sidewall tilt, the waveguide width is scanned from the single-mode cutoff condition to the whispering gallery regime and shows only a weak variation in levels of polarization conversion with microbend radius with $\pm 0.1 \mathrm{~dB}$ variation.

\section{CONCLUSION}

A new class of whispering gallery microbend design is studied. Dimensional tolerances are predicted to improve by an order of magnitude with respect to equivalent radius single-mode microbends. An analysis of the modes excited in the microbend near to the whispering gallery regime highlights the excitation of a stable mode group that is largely insensitive to fabrication incurred dimensional variations. $20 \mu \mathrm{m}$ radius microbends offer losses of order $0.2 \mathrm{~dB} / 180^{\circ}$, with smaller outer radii designs becoming increasingly susceptible to both waveguide coupling losses, and dimensional variation. Low polarization conversion is observed below $-25 \mathrm{~dB} / 90^{\circ}$ for sidewall tilts of less than $2^{\circ}$.

\section{ACKNOWLEDGMENT}

The authors acknowledge helpful discussions with V. Brulis from Photon Design.

\section{REFERENCES}

[1] A. Mekis, S. Fan, and J. D. Joannopoulos, "Bound states in photonic crystal waveguides and waveguide bends," Phys. Rev. B, vol. 58, pp. 4809-4817, 1998.

[2] A. Chutinan and S. Noda, "Waveguides and waveguide bends in two-dimensional photonic crystal slabs," Phys. Rev. B, vol. 62, pp. 4488-4492, 2000.

[3] T. Baba, N. Fukaya, and J. Yonekura, "Observation of light propagation in photonic crystal optical waveguides with bends," Electron. Lett., vol. 35, pp. 654-655, 1999.

[4] P. Buchmann and H. Kaufmann, "GaAs single-mode rib waveguides with reactive ion-etched totally reflecting corner mirrors," J. Lightw. Technol., vol. LT-3, no. 4, pp. 785-788, Aug. 1985.

[5] A. Himeno, H. Terui, and M. Kobayashi, "Loss measurement and analysis of high-silica reflection bending optical waveguides," J. Lightw. Technol., vol. 6, no. 1, pp. 41-46, Jan. 1988.

[6] R. U. Ahmad, F. Pizzuto, G. S. Camarda, R. L. Espinola, H. Rao, and R. M. Osgood, Jr., "Ultracompact corner-mirrors and T-branches in silicon-on-insulator," Photon. Technol. Lett., vol. 14, no. 1, pp. 65-67, 2002.

[7] D. G. Kim, Y. W. Choi, J. C. Yi, Y. Chung, C. Ozturk, and N. Dagli, "Multimode-interference-coupled ring resonators based on total-internal-reflection mirrors," Jpn. J. Appl. Phys., vol. 46, pp. 175-181, 2007.

[8] D. G. Sun, X. Li, D. Wang, Y. Hu, F. Luo, and T. J. Hall, "Modeling and numerical analysis for silicon-on-insulator rib waveguide corners," J. Lightw. Technol., vol. 27, no. 20, pp. 4610-4618, Oct. 2009.

[9] C. Manolatou, S. G. Johnson, S. Fan, P. R. Villeneuve, H. A. Haus, and J. D. Joannopoulos, "High-density integrated optics," J. Lightw. Technol., vol. 17, no. 9, pp. 1682-1692, Sep. 1999.

[10] C. Yeung, T. Rozzi, and G. Cerri, "Crosspolarisation coupling in curved dielectric rib waveguides," in IEE Proc.-Optoelectron., 1988, vol. 135 , no. 3 , pp. $281-284$.

[11] M. K. Smit, E. C. M. Pennings, and H. Blok, "A normalized approach to the design of low-loss optical waveguide bends," J. Lightw. Technol., vol. 11, no. 11, pp. 1737-1742, Nov. 1993. 
[12] B. M. A. Rahman, D. M. H. Leung, S. S. A. Obayya, and K. T. V. Grattan, "Numerical analysis of bent waveguides: Bending loss, transmission loss, mode coupling, and polarization coupling," Appl. Opt., vol. 47, no. 16, pp. 2961-2970, 2008.

[13] L. H. Spiekman, Y. S. Oei, E. G. Metaal, F. H. Groen, P. Demeester, and M. K. Smit, "Ultrasmall waveguide bends: The corner mirrors of the future?," in IEE Proc.-Optoelectron, 1995, vol. 142, no. 1, pp. $61-65$.

[14] A. Sakai, G. Hara, and T. Baba, "Propagation characteristics of ultrahigh- $\Delta$ optical waveguide on silicon-on-insulator substrate," Jpn. $J$. Appl. Phys., vol. 40, pp. L383-L385, 2001.

[15] M. Popović, K. Wada, S. Akiyama, H. A. Haus, and J. Michel, "Air trenches for sharp silica waveguide bends," J. Lightw. Technol., vol. 20, no. 9, pp. 1762-1772, Sep. 2002.

[16] S. T. Lim, C. E. Png, E. A. Ong, and Y. L. Ang, "Single mode, polarization-independent submicron silicon waveguides based on geometrical adjustments," Opt. Exp., vol. 15, no. 18, pp. 11061-11072, 2007.

[17] K. Sasaki, F. Ohno, A. Motegi, and T. Baba, "Arrayed waveguide grating of $70 \times 60 \mu \mathrm{m}^{2}$ size based on Si photonic wire waveguides," Electron. Lett., vol. 41, no. 14, pp. 861-862, 2005.

[18] Y. Barbarin, X. J. M. Leijtens, E. A. J. M. Bente, C. M. Louzao, J. R. Kooiman, and M. K. Smit, "Extremely small AWG demultiplexer fabricated on InP by using a double-etch process," IEEE Photon. Technol. Lett., vol. 16, no. 11, pp. 2478-2480, Nov. 2004.

[19] C. van Dam, L. H. Spiekman, F. P. G. M. van Ham, F. H. Groen, J. J. G. M. van der Tol, I. Moerman, W. W. Pascher, M. Hamacher, H. Heidrich, C. M. Weinert, and M. K. Smit, "Novel compact polarization converters based on ultra short bends," IEEE Photon. Technol. Lett., vol. 8 , no. 10 , pp. 1346-1348, Oct. 1996.

[20] S. S. A. Obayya, B. M. A. Rahman, K. T. V. Grattan, and H. A. El-Mikati, "Improved design of a polarization converter based on semiconductor optical waveguide bends," Appl. Opt., vol. 40, no. 30, pp. 5395-5401, 2001

[21] S. S. A. Obayya, B. M. A. Rahman, K. T. V. Grattan, and H. A. El-Mikati, "Analysis of polarisation rotation in cascaded optical waveguide bends," in IEE Proc.-Optoelectron, 2002, vol. 149, no. 2 , pp. $75-80$.

[22] A. Sakai, T. Fukazawa, and T. Baba, "Estimation of polarization crosstalk at a micro-bend in Si-photonic wire waveguide," J. Lightw. Technol., vol. 22, no. 2, pp. 520-525, Feb. 2004.

[23] F. Grillot, L. Vivien, S. Laval, and E. Cassan, "Propagation loss in single-mode ultrasmall square silicon-on-insulator optical waveguides," J. Lightw. Technol., vol. 24, no. 2, pp. 891-896, Feb. 2006.

[24] Z. Wang, G. Verschaffelt, Y. Shu, G. Mezosi, M. Sorel, J. Danckaert, and S. Yu, "Integrated small-sized semiconductor ring laser with novel retro-reflector cavity," Photon. Technol. Lett., vol. 20, no. 1, pp. 99-101, 2008.

[25] L. Xu, X. J. M. Leijtens, B. Docter, T. de Vries, E. Smalbrugge, F. Karouta, and M. K. Smit, "MMI-reflector: A novel on-chip reflector for photonic integrated circuits," presented at the presented at the Eur. Conf. Opt. Commun., Austria, 2009, Paper P2.24.

[26] J. Van Campenhout, P. Rojo-Romeo, P. Regreny, C. Seassal, D. Van Thourhout, S. Verstuyft, L. Di Cioccio, J.-M. Fedeli, C. Lagahe, and R. Baets, "Electrically pumped InP-based microdisk lasers integrated with a nanophotonic silicon-on-insulator waveguide circuit," Opt. Exp., vol. 15, no. 11, pp. 6744-6749, 2007.

[27] J. W. Strutt, "Whispering gallery modes," Philos. Mag., Series, vol. 6 , no. 20 , pp. 1001-1004, 1910 .
[28] J. Heebner, R. Grover, and T. Ibrahim, Optical Microresonators, Theory, Fabrication and Applications. Berlin, Germany: Springer, 2008.

[29] N. C. Frateschi and A. F. J. Levi, "The spectrum of microdisk lasers," J. Appl. Phys., vol. 80, pp. 644-653, 1996.

[30] R. P. Wang and M. M. Dumitrescu, "Optical modes in semiconductor microdisk lasers," IEEE J. Quantum Electron., vol. 34, no. 10, pp. 1933-1937, Oct. 1998.

[31] E. A. J. Marcatili, "Bends in optical guides," Bell Syst. Tech. J., vol. 48 , pp. $2103-2132,1969$

[32] S. Sheem and J. R. Whinnery, "Modes of a curved surface waveguide for integrated optics," Wave Electron., vol. 1, pp. 105-106, 1974.

[33] S. Sheem and J. R. Whinnery, "Guiding by single curved boundaries in integrated optics," Wave Electron., vol. 1, pp. 61-68, 1974.

[34] E.-G. Neumann, "Curved dielectric optical waveguides with reduced transition losses," in IEE Proc. Microw. Opt. Antenna, 1982, vol. 129 , no. 5, pp. 278-280.

[35] V. Brulis,, Photon Design, Private Communication.

[36] FIMMWAVE Software, Photon Design. Oxford, UK.

[37] A. S. Sudbø, "Film mode matching: A versatile numerical method for vector mode field calculations in dielectric waveguides," Pure Appl. Opt., J. Eur. Opt. Soc., vol. 2, no. 3, pp. 211-233, 1993.

[38] D. F. G. Gallagher and T. P. Felici, "Eigenmode expansion methods for simulation of optical propagation in photonics - Pros and cons," presented at the presented at the Proc. SPIE 4987, Integrated Optics: Devices, Mater. Technol. VII, , vol. 69, 2003.

[39] OMNISIM Software, Photon Design. Oxford, UK.

[40] J.-P. Berenger, "A perfectly matched layer for the absorption of electromagnetic waves," J. Comput. Phys., vol. 114, pp. 185-200, 1994.

Ripalta Stabile received the Master degree in electrical engineering from the Politecnico of Bari, Bari, Italy, in 2004. In 2005, she joined the Soft Matter Nanotechnology Group at National Nanotechnology Laboratory, Lecce, Italy, where she received the Ph.D. degree in nanoscience in 2008.

In 2009, she moved to COBRA Research Institute, Technical University of Eindhoven, Eindhoven, The Netherlands, where she was appointed as Postdoctoral Researcher. She is currently with COBRA Research Institute, Technical University of Eindhoven. Her research interests include the design and the simulation of organic and inorganic photonic devices, and the nanofabrication and characterization on highly integrated photonic circuits.

Kevin A. Williams received the B.Eng. degree in electrical engineering from the University of Sheffield, Sheffield, U.K., in 1991 and the Ph.D. degree in physics from the University of Bath, Bath, U.K., in 1995.

He moved to the University of Cambridge, Cambridge, U.K., in 2001, where he was a Lecturer and Fellow at Churchill College. In 2006, he moved to COBRA Research Institute, Technical University of Eindhoven, Eindhoven, The Netherlands, with a Marie Curie Chair. His research interests include the design, realization, and demonstration of high-speed integrated photonic circuits.

Dr. Williams was awarded a University Research Fellowship from the Royal Society, U.K., in 1996. He received a VICI Award from the Netherlands Organisation for Scientific Research (NWO) in 2011. 